\title{
Physical properties and caffeine release from creams prepared with different oils
}

\author{
Katarzyna Wojciechowska, Maria Zun, Dorota Dwornicka, Katarzyna Swiader, \\ Regina Kasperek, Ewa Poleszak
}

Chair and Department of Applied Pharmacy, Medical University of Lublin, Chodzki 1, 20-093 Lublin, Poland

\begin{tabular}{l}
\hline ARTICLE INFO \\
\hline Received 15 October 2014 \\
Accepted 24 November 2014
\end{tabular}

Keywords:

caffeine release,

creams,

rheology.

\begin{abstract}
Caffeine is a methylxanthine typically found in the Coffee Arabica L plant. Generally, caffeine is well-known as a orally administered mild stimulant of the central nervous system. However, for cosmetic purpose, caffeine is an active compound ingredient, at 7\% concentration, in several anticellulite products. The efficiency of this mode of delivery is not fully understood. Hence, the aim of the study was to ascertain the effectiveness of particular carriers to release this ingredient. In so doing, we prepared six creams based upon different oils (Sesame oil, Rice oil, Walnut oil, Coconut oil, Sweet almond oil and Jojoba oil), containing 5\% of caffeine, and compared the release of the substance from the obtained preparations. Initially, all of the creams were subjected to a variety of physical tests, among these being for slippage and spreadability. Furthermore, their rheological properties were evaluated. Subsequently, the creams were tested for caffeine release. In the slippage and spreadability tests, the coconut oil-based cream was revealed as having the best parameters. However, the rheological tests showed that all of the preparations had the pseudoplastic character of flowing according to the Ostwald de Waele power law model. The power low index (n) for all the preparations was from $0.2467-0.3179$ at $20^{\circ} \mathrm{C}$ and $0.2821-0.3754$ at $32^{\circ} \mathrm{C}$. At $20^{\circ} \mathrm{C}$, the Sesame oil-, Walnut oil-, Sweet almond oil- and Jojoba oil-based creams were thixotropic, but at $32^{\circ} \mathrm{C}$, thixotropy appeared only in the Walnut oil-based creams.

The release studies, conducted by way of an extracting chamber (according to Polish Pharmacoeia IX) in the Paddle Apparatus (according to Polish Pharamcopoeia IX), showed that the amount of released caffeine is the largest in the case of Jojoba oil-based cream, at $85.23 \% \pm 0.8 \%$ (SD), and the least in the case of Coconut oil-based cream, at $62,78 \% \pm 0.87 \%(\mathrm{SD})$.
\end{abstract}

\section{INTRODUCTION}

Caffeine is a compound of natural origin belonging to the purine alkaloids. It is successfully used in cosmetics for dry and sensitive skin (especially for aging skin), as well for topical treatment of the swollen, dark appearance around the eyes called 'puffy eyes'. It is considered to be active in cell dehydration and blood vessel constriction. In addition, it purportedly has a stimulating effect on the cutaneous microcirculation [9]. Moreover, research indicates that the use of caffeine in hair care products for men reduces and slows down hair loss [11]. In addition, because of its antioxidant

Corresponding author

e-mail: kgierucka@wp.pl properties, caffeine has been shown to be a protector against the effects of UVB radiation [3].

Caffeine penetrates the skin very easily. This facilitates its absorption and action. It acts directly on adipose cells, promoting lipolysis and inhibiting phosphodiesterase. What is more, it activates the triglyceride lipase enzyme and breaks triglycerides down into free acids and glycerol. Therefore, for cosmetic purpose, caffeine is used as an active compound in several anti-cellulite products $[5,15]$. Commercially available topical formulations usually contain caffeine at $3 \%$, while the anti-cellulite products see up to $7 \%$ [8]. Several studies have been conducted with certain natural oils being used as a cream base, and it has been shown that these oils alone have a positive moisturizing effect on the 
skin, rendering it soft and smooth [4,12]. Information on the efficiency of such oils as transference agents and carriers of active ingredients is rather scarce, although work has been done on the effect of Olive oil, Corn oil, Ricine oil and synthetic Isopropyl myristate on the solubility of tretinoin in o/w creams. As a result, Olive oil, Avocado oil, Arachid oil and Apricot kernel oil are used commercially for producing very good stability creams/ emulsions o/w [7].

The typical oils used in creams and milk lotions are Jojoba oil, Shea butter, Avocado oil, Sweet almond oil and Coconut oil $[2,13,16,20,21]$. Obviously, these oils have an effect on the physical properties and stability of the active compounds contained in the preparations.

However, not much research has been done on understanding the efficiency of such oils (as creams) in delivering the active ingredient, caffeine. Nor is there much information on their properties as cosmetic creams. The aim of our research was, therefore, to examine the physical and rheological properties of topical creams based on oils such as Sesame oil, Rice oil, Walnut oil, Coconut oil, Sweet almond oil and Jojoba oil, and to ascertain their ability to release caffeine.

\section{MATERIALS AND METHODS}

\section{Chemicals}

Anhydrous caffeine was received from Sigma- Aldrich Chemie Gmbh, Germany; Cetylic alcohol - Galenic Laboratory Olsztyn; Methyl Glucose Sesquistearate (MGS) Sigma SPA, IMCD Warsaw, Sesame oil, Rice oil, Walnut oil, Coconut oil, Sweet almond oil, Jojoba oil were received as a gift from Sigma SPA, IMCD, Warsaw.

\section{Apparatus}

Rheotest 2 Medingen viscometer (NRD); Extensometer; Ultratermostat MLW UH 4 - VEB MLW Medingen Germany; Mixer Cito-UNGUATOR c/s - EPRUS; Magnetic stirrer-Type MM 6, Spectrophotometer Helios Omega UV-Vis, SpectroLab, Poland; Paddle Apparatus Erweka DT-600, Germany; Dialysis membrane Visking® Serva; extraction chamber designed according to Polish Pharmacopoeia IX, made in Zakład Mechaniki Precyzyjnej, Lublin.

\section{Preparations}

Six kinds of preparations (P1, P2, P3, P4, P5, P6) were fashioned. Their composition is given in Table 1. All preparations were made by dissolving caffeine in warm water (phase 1), then cetylic alcohol, Methyl Glucose Sesquistearate (MGS) and the particular oil of interest were combined (phase 2). Subsequently, phase 2 was added to phase 1 and stirred to obtain a homogenous cream. All preparations were additionally homogenized in the Unguator ${ }^{\circledR}$ in order to obtain a uniform consistency.

\section{Evaluation of the physical properties of preparations}

\section{Determination of emulsion type}

Based on the indicative method presented in the Polish Pharmacopoeia VI [18] and observation under microscope, it was determined that these emulsions are an oil in water type.
Table 1. The composition of the preparations with caffeine

\begin{tabular}{|l|c|c|c|c|c|c|}
\hline Ingredients (\%) & P1 & P2 & P3 & P4 & P5 & P6 \\
\hline Water & 70 & 70 & 70 & 70 & 70 & 70 \\
\hline Anhydrous caffeine & 5 & 5 & 5 & 5 & 5 & 5 \\
\hline Cethylic alcohol & 1 & 1 & 1 & 1 & 1 & 1 \\
\hline MGS & 3 & 3 & 3 & 3 & 3 & 3 \\
\hline Sesame oil & 21 & - & - & - & - & - \\
\hline Rice oil & - & 21 & - & - & - & - \\
\hline Walnut oil & - & - & 21 & - & - & - \\
\hline Coconut oil & - & - & - & 21 & - & - \\
\hline Sweet almond oil & - & - & - & - & 21 & - \\
\hline Jojoba oil & - & - & - & - & - & 21 \\
\hline
\end{tabular}

\section{Determination of the spreadability}

Determination of the spreadability was conducted in an extensometer at $20^{\circ} \mathrm{C} \pm 0.1^{\circ} \mathrm{C}[1,10]$. The relationship between the load and the stretched surface of the preparations $\left(\mathrm{mm}^{2}\right)$ is shown in Figure 1.

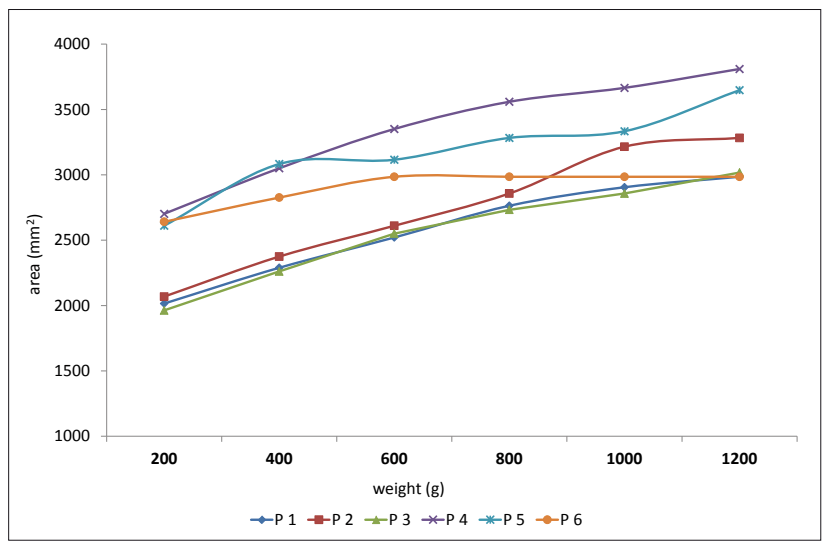

Figure 1. Spreadability of the preparations P1, P2, P3, P4, P5, P6

\section{Determination of the slip}

In the slip test, the load which allowed the movement of two plates with the preparation between them, was measured. The average of three measurements is shown in Figure 2 .

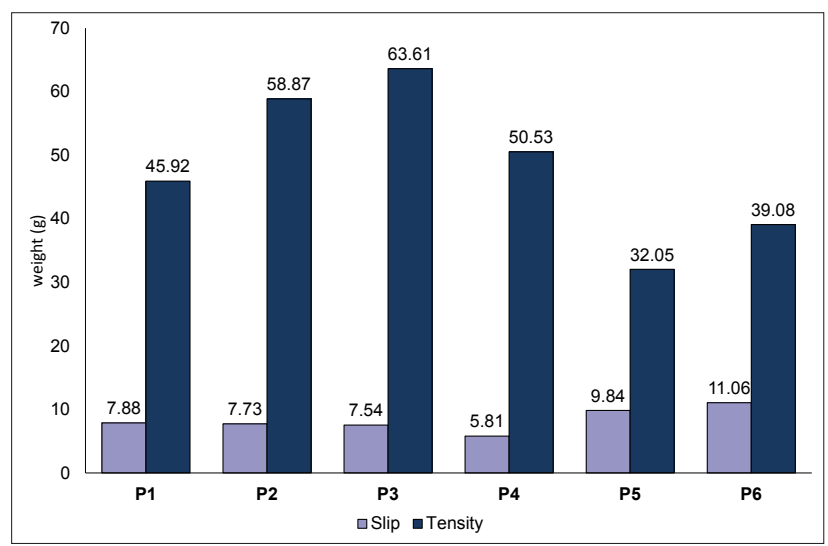

Figure 2. Slip and tenacity of the preparations: P1, P2, P3, P4, P5, P6 


\section{Determination of the tenacity}

The tenacity test was conducted in a special apparatus fabricated according to information found in Münzel [14]. The apparatus consists of two stainless steel plates, $27 \mathrm{~mm}$ in diameter. The lower plate is attached to a base; the upper is suspended by the string of a balance dish. On the lower plate, an equal amount of cream was applied and covered with a top plate. About $5 \mathrm{~g}$ was then added every 20 seconds until the detachment of the plate came about. The average results of six measurements with the standard deviation (SD) are presented in Figure 2.

\section{Rheological studies}

Ascertaining the rheological properties of the skin preparations enabled a prediction to be made of their behavior during production, storage and use. Moreover, this research allow a determination of the quality and utility of the preparations $[1,12,19]$. The studies were conducted at $20^{\circ} \mathrm{C}$ and at $32{ }^{\circ} \mathrm{C}$, using a "RHEOTEST-2" with thermostat. The measurements were performed at a shear rate (Dr) between 1.5-656.0 $\mathrm{s}^{-1}$. The relative viscosity coefficient $(\mathrm{k})$, power law index $(\mathrm{n})$, hysteresis loop area $(\Delta \mathrm{H})$ are given in Table 2.

Table 2. The calculated values of $\mathrm{n}, \mathrm{k}, \Delta \mathrm{H}$ for creams at $20^{\circ} \mathrm{C}$ and $32^{\circ} \mathrm{C}$

\begin{tabular}{|c|c|c|c|c|c|c|c|}
\hline Temp. $\left({ }^{\circ} \mathrm{C}\right)$ & & $\mathrm{P} 1$ & $\mathrm{P} 2$ & $\mathrm{P} 3$ & $\mathrm{P} 4$ & $\mathrm{P} 5$ & $\mathrm{P} 6$ \\
\hline \multirow{3}{*}{$20{ }^{\circ} \mathrm{C}$} & $\mathrm{k}$ & 85.87 & 171.38 & 150.72 & 135.92 & 174.3 & 130.74 \\
\cline { 2 - 8 } & $\mathrm{n}$ & 0.3179 & 0.2645 & 0.3002 & 0.3097 & 0.2467 & 0.3088 \\
\cline { 2 - 8 } & $\Delta \mathrm{H}$ & 48577.63 & - & 43268.56 & - & 32576.75 & 36546.6 \\
\hline \multirow{3}{*}{$32{ }^{\circ} \mathrm{C}$} & $\mathrm{k}$ & 97.84 & 113.49 & 147.6 & 83.98 & 131.54 & 98.39 \\
\cline { 2 - 8 } & $\mathrm{n}$ & 0.3476 & 0.2821 & 0.2932 & 0.3754 & 0.2904 & 0.3442 \\
\cline { 2 - 8 } & $\Delta \mathrm{H}$ & - & - & 42043.39 & - & - & - \\
\hline
\end{tabular}

$\mathrm{k}$ - relative viscosity coefficient

$\mathrm{n}$ - power low index

$\Delta \mathrm{H}-$ hysteresis loop area (mPas)

\section{Drug release studies}

\section{UV spectrum analysis of anhydrous caffeine}

A standard stock solution was obtained by dissolving $70 \mathrm{mg}$ of caffeine in $100 \mathrm{ml}$ of phosphate buffer $\mathrm{pH} 6.8$. Then $10 \mathrm{ml}$ of the solution was taken and transferred into a $100 \mathrm{ml}$ volumetric flask. The volume was completed with phosphate buffer $\mathrm{pH} 6.8$.

The estimation of caffeine was carried out by spectrophotometer. The standard solution was scanned in the range of 200-400 nm to obtain the maximum wavelength.

The maximum absorbance was at $273 \mathrm{~nm}$.

\section{Calibration graph of caffeine}

Standard solutions of caffeine at concentrations $0.5,1$, $2,4,10,20 \mu \mathrm{g} / \mathrm{ml}$ were prepared. The absorbances of these solutions were measured spectrophotometrically against a blank of phosphate buffer $\mathrm{pH} 6.8$ at $273 \mathrm{~nm}$. This procedure was repeated five times. The standard curve ABS $=\mathrm{f}(\mathrm{c})$ is presented in Figure 3. The statistic estimation of standard curve is presented in Table 3.
Table 3. The statistic estimation of standard curve ABS $=\mathrm{f}(\mathrm{c})$

\begin{tabular}{|c|c|c|c|c|}
\hline $\begin{array}{c}\text { Concentration } \\
(\mu \mathrm{g} / \mathrm{ml})\end{array}$ & Precision & $\begin{array}{c}\text { ABS } \\
(\text { average })\end{array}$ & $\pm \mathrm{SD}$ & $\pm \mathrm{RSD} \%$ \\
\hline \multirow{2}{*}{1} & DP & 0.046 & 0.0012 & 2.692 \\
\cline { 2 - 5 } & BDP & 0.046 & 0.0016 & 3.425 \\
\hline \multirow{2}{*}{4} & DP & 0.191 & 0.0032 & 1.704 \\
\cline { 2 - 5 } & BDP & 0.190 & 0.0035 & 1.856 \\
\hline \multirow{2}{*}{20} & DP & 0.986 & 0.0020 & 0.198 \\
\cline { 2 - 5 } & BDP & 0.987 & 0.0027 & 0.270 \\
\hline
\end{tabular}

ABS - absorbance, SD - standard deviation, RSD - relative standard deviation, DP - day precision $(n=5), B D P-$ between day precision $(n=15)$

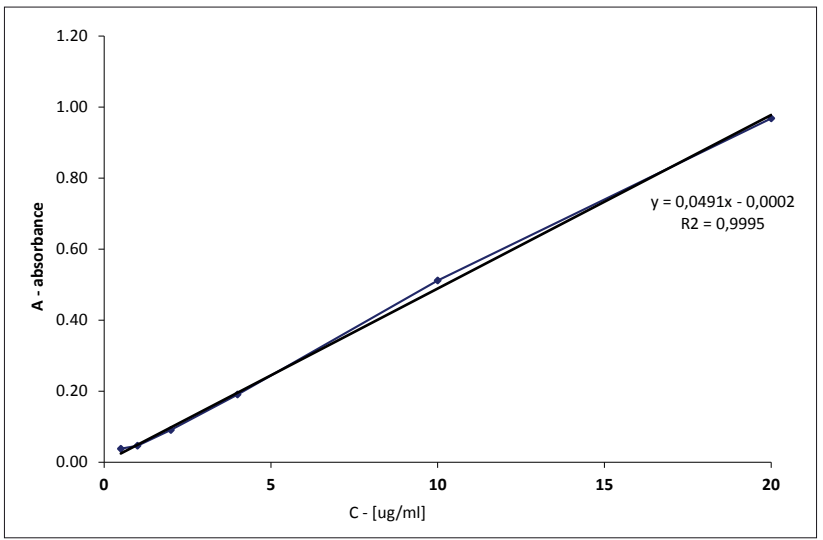

Figure 3. Standard curve for anhydrous caffeine $A B S=f(c)$

\section{The estimation of caffeine content}

Three $1 \mathrm{~g}$ samples of preparations P1, P2, P3, P4, P5, P6 were accurately weighed. The samples were transferred into volumetric flasks and completed with phosphate buffer to $100 \mathrm{ml}$. Then $10 \mathrm{ml}$ of each solution was diluted to $100 \mathrm{ml}$ with the same solvent and the content of caffeine was determined spectrophotometrically at $273 \mathrm{~nm}$. The determination was repeated three times against a blank of phosphate buffer $\mathrm{pH}$ 6.8. The blank placebo (creams made in the same way, but without caffeine) showed no absorbance. The concentration of caffeine in all samples were determined by way of the regression equation. The quantities of caffeine were calculated based on the results of the concentration and taking into account the dilutions of the samples. The estimation of caffeine content in the preparations is presented in Table 4.

Table 4. The estimation of caffeine content in the preparations P1, P2, P3, P4, P5, P6

\begin{tabular}{|c|c|c|c|c|}
\hline Preparation & $\begin{array}{c}\text { Content } \\
(\mu \mathrm{g} / \mathrm{ml})\end{array}$ & $\pm S D$ & \pm RSD \% & $\begin{array}{c}\text { Recovery } \\
(\%)\end{array}$ \\
\hline P1 & 25.207 & 0.586 & 2.323 & 100.83 \\
\hline P2 & 25.431 & 0.543 & 2.146 & 101.73 \\
\hline P3 & 25.312 & 0.646 & 2.552 & 101.25 \\
\hline P4 & 25.405 & 0.469 & 1.846 & 101.62 \\
\hline P5 & 25.413 & 0.399 & 1.569 & 101.65 \\
\hline P6 & 25.165 & 0.483 & 1.920 & 100.66 \\
\hline
\end{tabular}

SD - standard deviation, RSD - relative standard deviation

\section{Caffeine release study}

Caffeine release studies were conducted by first being prepared in a Paddle Apparatus, according to instructions found in Polish Pharmacopoeia IX [6,17], in the presence of phosphate buffer $(\mathrm{pH}=6.8)$ at the volume $900 \mathrm{ml}$, at $32^{\circ} \mathrm{C} \pm 1^{\circ} \mathrm{C}$. 
The speed rate of the paddle was $75 \mathrm{rpm}$. Subsequent to this, the preparation was processed by the dialysis method, in an extraction chamber, according to information supplied in Polish Pharmacopoeia IX [17]. After preparation in the Paddle Apparatus, $2 \mathrm{~g}$ of each preparation was weighed into the extraction chamber. The releasing was conducted through a dialysis membrane (Visking $®$ Serva) with pore diameter $0.45 \mu \mathrm{m}$ with the same area previously hydrated by way of an acceptor solution. The samples $(5 \mathrm{ml})$ were taken after 15, 30, 60, 120, $180 \mathrm{~min}$, and the rest was completed with the phosphate buffer to the starting volume. Percent of the release of caffeine was determined spectrophotometrically at $273 \mathrm{~nm}$, and the caffeine concentration was calculated from the regression equation, taking into account the dilution. The results are showed as the average of five calculations in Figure 4.

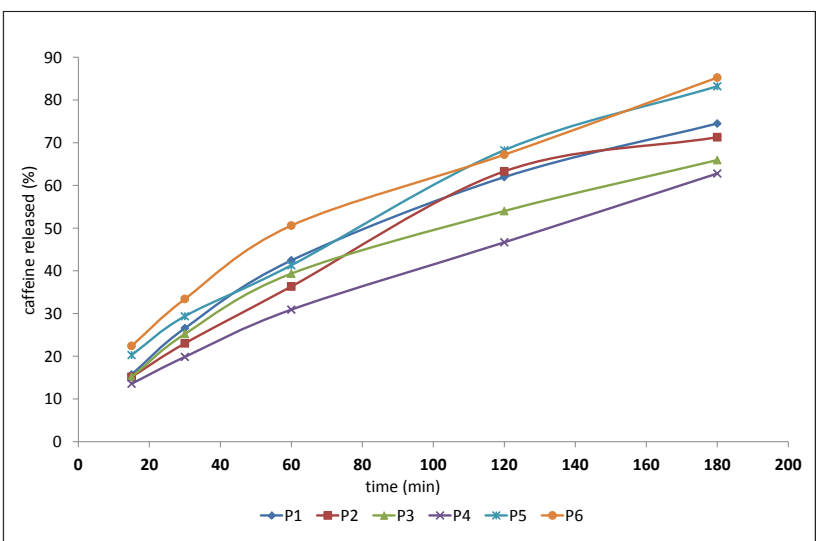

Figure 4. Sum percent released of caffeine from the preparations P1, P2, P3, P4, P5, P6.

\section{RESULTS AND DISCUSSION}

Six preparations (P1, P2, P3, P4, P5, P5, P6), based upon different oils (Sesame oil, Rice oil, Walnut oil, Coconut oil, Sweet almond oil, Jojoba oil, respectively) modified with the addition of $5 \%$ of caffeine, were prepared. All preparations were found to be homogeneous by way of organoleptic examination, and all preparations were oil in water emulsions. The fabricated creams based upon Sesame oil and Jojoba oil had a yellowish color, the rest were almost white. The Sesame oil cream had a characteristic Sesame smell. All preparations had very good spreadability on the skin.

The tests showed that the Coconut oil cream and the Sweet almond oil cream had the best spreadability: at the load of $1200 \mathrm{~g}$, the spreadability surface was $3809.95 \mathrm{~mm}^{2}$ $\pm 51.44 \mathrm{~mm}^{2}$ for the Coconut oil cream, and $3647.66 \mathrm{~mm}^{2} \pm$ $25.26 \mathrm{~mm}^{2}$ for the Sweet almond oil cream. For the Jojoba oil cream, the spreadability was independent of the load, and its value was $2640.74 \mathrm{~mm}^{2} \pm 148.71 \mathrm{~mm}^{2}$ for a load of $200 \mathrm{~g}$, and $2985.18 \mathrm{~mm}^{2} \pm 198.16 \mathrm{~mm}^{2}$ at the loads of $600 \mathrm{~g}, 800 \mathrm{~g}, 1000 \mathrm{~g}$ and $1200 \mathrm{~g}$. The other preparations had a similar spreadability from about $2000 \mathrm{~mm}^{2}$ at the load of $200 \mathrm{~g}$, to $3000 \mathrm{~mm}^{2}$ at the load of $1200 \mathrm{~g}$.

The results of slip tests for creams based upon Sesame oil, Rice oil and Walnut oil were similar - 7.54 g-7.88 g. The lower slip figure was that of the Coconut oil cream at
$5.81 \mathrm{~g} \pm 0.02 \mathrm{~g}$, and the higher slip figure was for Jojoba oil cream at $11.06 \mathrm{~g} \pm 0.14 \mathrm{~g}$.

In the tenacity tests, the lower tenacity figure was observed for the Sweet almond oil cream at $32.05 \mathrm{~g} \pm 2.52 \mathrm{~g}$, and the highest figure was $63.61 \mathrm{~g} \pm 2.12 \mathrm{~g}$ for the Walnut oil cream.

The rheological studies showed that all the creams had a pseudoplastic character of flowing at $20^{\circ} \mathrm{C}$ and $32^{\circ} \mathrm{C}$ according to the Ostwald de Waele's power law model. The power low index (n) for all the preparations was 0.2467-0.3179 at $20^{\circ} \mathrm{C}$, and $0.2821-0.3754$ at $32^{\circ} \mathrm{C}$. The viscosity of the obtained preparations at the shear rate $\mathrm{D}_{\mathrm{r}}=24.3 \mathrm{~s}^{-1}$ and at $20^{\circ} \mathrm{C}$, was: 1171,41 mPas, $2053.93 \mathrm{mPas}, 2006.44 \mathrm{mPas}$, $1804.60 \mathrm{mPas}, 1590.91 \mathrm{mPas}$ and $1844.18 \mathrm{mPas}$; and at $32^{\circ} \mathrm{C}$ was: $1329.71 \mathrm{mPas}, 1210.99 \mathrm{mPas}, 1947.08 \mathrm{mPas}$, 1282. $22 \mathrm{mPas}, 1464.27 \mathrm{mPas}, 1298.05 \mathrm{mPas}$, respectively, for creams of Sesame oil, Rice oil, Walnut oil, Coconut oil, Sweet almond oil and Jojoba oil. At $20^{\circ} \mathrm{C}$, the creams of Sesame oil, Walnut oil, Sweet almond oil and Jojoba oil had thixotropy. The histeresis loop area was the highest for Sesame oil cream (at $48577.63 \mathrm{mPas}$ ), and the lowest for Sweet almond oil cream (at $32576.75 \mathrm{mPas}$ ). At $32^{\circ} \mathrm{C}$, thixotropy appeared only in the Walnut oil cream.

The quantitative analysis of caffeine was adopted from Polish Pharmacopeia IX.

The selectivity of the used method for the analysis of caffeine was evaluated by the analysis of blank placebos (creams made in the same way, but without the addition of caffeine), and the resulting absorbance readings were the same as a blank reagent, inferring that no interference was generated from the placebos. These results confirm the selectivity of the used method.

To evaluate linearity, standard solutions in the range of $0.50-20 \mu \mathrm{g} / \mathrm{ml}$ were assayed. The calibration curve expressed by the regression equation is presented in Table 3 . Good linearity between the absorbance and the concentration of caffeine was observed with the coefficient correlation $(\mathrm{r}=0.9995)$.

To check the precision of the used method, solutions containing three different concentrations of caffeine were prepared and analyzed in five replicates, during the same day (intraday precision) and three consecutive days (interday precision). These results are summarized in Table 3 . The low values of the percentage relative standard deviation (RSD: $0.1978-2.6918 \%$ for intraday) and (RSD: 0.2698-3.4245\% for interday) indicate the high precision of the used method.

The same method was applied for the determination of caffeine in the prepared creams. The drug content in the preparations was found to be $5.041 \% \pm 2.32 \%$ (RSD) for Sesame oil, 5.056\% $\pm 1.974 \%$ (RSD) for Rice oil, 5.062\% $\pm 2.552 \%$ (RSD) for Walnut oil, $5.047 \% \pm 1.235 \%$ (RSD) for Coconut oil, $5.072 \% \pm 1.272 \%$ (RSD) for Sweet almond oil and $5.033 \% \pm 1.92 \%$ (RSD) for Jojoba oil. The accuracy of this method was confirmed after application of Student's t-test.

The release studies showed the best caffeine release came about from the Jojoba cream, at $85.23 \% \pm 0.8 \%$ (SD) after $180 \mathrm{~min}$, and the worst from the Coconut oil cream, at $62.78 \% \pm 0.87 \%$ (SD). Regarding the other creams, the caffeine release was, respectively: $74.49 \% \pm 0.86 \%$ (SD) 
for Sesame oil, 71.28\% \pm 0.94\% (SD) for Rice oil, $65.93 \%$ $\pm 0.65 \%$ (SD) for Walnut oil, and $83.22 \% \pm 0.83 \%$ (SD) for Sweet almond oil.

\section{CONCLUSIONS}

Our results showed that:

1. The Coconut oil cream had the best spreadability, but the amount of the released caffeine was the worst among all the cream preparations.

2. The highest amount of caffeine release was from the Jojoba oil cream preparation.

3. All the cream preparations had a pseudoplastic character of flowing at $20^{\circ} \mathrm{C}$ and $32^{\circ} \mathrm{C}$.

4. The Walnut oil cream alone showed thixotropic properties at $20^{\circ} \mathrm{C}$ and at $32^{\circ} \mathrm{C}$.

\section{REFERENCES}

1. Achim M. at al.: Topical dosage forms containing fluid extract of ruscus aculeatus: Formulation, preparation and physical characterization. Clujul Medical 83, 99-103, 2010

2. Akhtar N. et al.: Formulation and in vitro evaluation of a cosmetic emulsion from almond oil. Pak. J. Pharm. Sci., 21, 430-437, 2008.

3. Azam S. et al.: Antioxidant and pro-oxidant properties of caffeine, theobromine and xanthine. Med. Sci. Monit. 9, 325-330, 2003.

4. Ballamann C., Mueller BW.: Stabilizing effect of cetostearyl alcohol and glyceryl monostearate as co-emulsifiers on hydrocarbon-free O/W glyceride creams. Pharm. Dev. Technol., 13, 433-435, 2008.

5. Bertin et al.: A double blind evaluation of activity of an anticellulite product containing retinol, caffeine and ruscogenine by a combination of several non invasive methods. J. Cosmet. Sci. 52, 199-210, 2001
6. Bottari F.: Influence of drug concentration on in-vitro release of salicylic acid from ointment bases. J. Pharm. Sci., 63, 1979-1983, 1974.

7. Brisaert M., Plaizer-Vercammen JA.: Investigation on the photostability of tretinoin in creams. Int. J. Pharm., 4, 56-61, 2007.

8. Dias M., et al.: Topical delivery of caffeine from some commercial formulations. Int. J. Pharm. 182, 41-47, 1999.

9. Doris H. et al.: Cosmeceuticals for cellulite seminaris in cutaneous. Medicine and Surgery, 30, 167-170, 2011.

10. Fiebieg A., Janicki St., Sznitowska M.: Farmacja stosowana. PZWL 2004.

11. Fischer T.W. et al.: Effect of caffeine and testosterone on the proliferation of human hair follicles in vitro. Int. J. Dermatol., 46, 27-35, 2007.

12. Jimenez-Soriano M.M., Fresno- Contreras M.J., Selles F.: Development of a cream from a self-emulsifying base and moisturizing actives. II Farmaco, 2001, 56, 513-522.

13. Konning GH., Mital HC. Study of shea butter. 4. Stability of medicaments in shea butter ointment and creams. Pharm. Acta Helv. 49, 192-196, 1974.

14. Krówczyński L.: Technologia postaci leków PZWL, Warszawa, 1969.

15. Omar L. et al.: Evaluation of the effects of caffeine in the microcirculation and edema on thighs and buttocks using the orthogonal polarization spectral imaging and clinical parameters. J. Cosmet. Dermatol. 6, 102-107, 2007.

16. Oyedeji F., Okeke I.: Comparative analysis of moisturizing creams from vegetable oils and paraffin oil. J. App. Sci., 5, 157-160, 2010.

17. Polish Pharmacopea IX, Urząd Rejestracji Produktów Leczniczych, Wyrobów Medycznych i Produktów Bójczych. Warszawa 2011.

18. Farmakopea Polska VI, PZWL, 2002

19. Tamburic S.: Aging of polymer stabilized creams: rheological viewpoint. Cosmet. and Toilet. 115, 43-46, 2000.

20. Taguchi M., Kunimoto T.: Jojoba wax in cosmetic creams and lotions. Cosmet. and Toilet. 95, 39-41, 1980.

21. Wendel O.W.: Jojoba - promising liquid cosmetic wax. Cosmet and Toilet. 95, 41-54, 1980. 